\title{
Comparison of internal target volumes defined by three- dimensional, four-dimensional, and cone-beam computed tomography images of a motion phantom
}

\author{
Yu Wang ${ }^{1 \#}$, Tao Liu ${ }^{1,2 \#}$, Huiqin Chen ${ }^{3}$, Penggang Bai ${ }^{4}$, Qiong Zhan ${ }^{1,2}$, Xiaohua Liang ${ }^{1,2}$ \\ ${ }^{1}$ Department of Oncology, Huashan Hospital North, Fudan University, Shanghai, China; ${ }^{2}$ Department of Oncology, Huashan Hospital, Fudan \\ University, Shanghai, China; ${ }^{3}$ Department of Radiotherapy, Zhangzhou Municipal Hospital, Fujian Medical University, Zhangzhou, China; \\ ${ }^{4}$ Department of Radiotherapy, Fujian Provincial Cancer Hospital, Fujian Medical University, Fuzhou, China \\ Contributions: (I) Conception and design: Y Wang; (II) Administrative support: X Liang, Q Zhan; (III) Provision of study materials or patients: H \\ Chen, P Bai; (IV) Collection and assembly of data: Y Wang, H Chen; (V) Data analysis and interpretation: Y Wang, T Liu; (VI) Manuscript writing: \\ All authors; (VII) Final approval of manuscript: All authors. \\ "These authors contributed equally to this work. \\ Correspondence to: Qiong, Zhan, MD; Xiaohua Liang, PhD. Department of Oncology, Huashan Hospital North, Fudan University, 108th Luxiang \\ Road, Baoshan District, Shanghai, China. Email: zjoan2121@163.com; liangxiaohua@csco.ac.cn.
}

Background: To explore the variations of the gross tumor volume (GTV) from different three-dimensional computed tomography (3DCT) scan modes and the consistency of internal target volume (ITV) between different 3DCT, cone-beam computed tomography (CBCT) and four-dimensional computed tomography (4DCT) scan, a study using a motion phantom simulating sinusoidal movement was conducted.

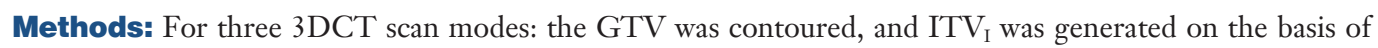
GTV with a $10-\mathrm{mm}$ margin while $\mathrm{ITV}_{\mathrm{II}}$ and $\mathrm{ITV}_{\mathrm{III}}$ with a $0-\mathrm{mm}$ margin on the motion direction. ITV $\mathrm{CBCT}_{\mathrm{C}}$ and $\mathrm{ITV}_{\text {MIP }}$ were contoured on the images of CBCT and maximum-intensity projection (MIP) reconstructed 4DCT images. The centroid position shifts of ITVs were analyzed. The volume consistency between ITV ITV $_{\text {II }}$ ITV III $_{\text {and ITV }}$ MIP were evaluated by calculating the Dice similarity coefficient (Dsc) and the value of $\Delta$ Volume $(\Delta \mathrm{V})$. Furthermore, the 3DCT and CBCT images from 12 NSCLC patients were retrospectively collected, then the Dsc and $\Delta \mathrm{V}$ were calculated.

Results: The mean \pm standard deviation of centroid position of $\operatorname{ITV}_{\mathrm{I}}, \mathrm{ITV}_{\mathrm{II}}$ and ITV $\mathrm{III}$ were 2.3 $\pm 4.7,2.6 \pm 4.0$, and $1.0 \pm 1.4 \mathrm{~mm}$, respectively. The mean \pm standard deviation of Dsc between ITV I ITV $\mathrm{II}, \mathrm{ITV}_{\mathrm{III}}$ and ITV $\mathrm{ITI}_{\mathrm{M}}$ were $0.78 \pm 0.77,0.86 \pm 0.1$, and $0.94 \pm 0.05$, respectively. The $\Delta V$ of $\mathrm{ITV}_{\mathrm{I}}, \mathrm{ITV}_{\mathrm{II}}, \mathrm{ITV}_{\mathrm{III}}$ were $29.67 \%, 17.22 \%$, and $6.46 \%$, respectively. The ITV from CBCT showed a deduction rate of $3.1-9.3 \%$ compared to 4DCT. For the patients, the mean Dsc and $\Delta \mathrm{V}$ between ITV $\mathrm{I}_{\mathrm{I}}$ and ITV $\mathrm{IBCT}_{\mathrm{CBC}}$ were 0.50 and $60.76 \%$.

Conclusions: The GTV acquired from 3DCT scan mode I possessed great deviation of centroid position and target volume. ITV on the basis of this GTV was significantly larger than ITV ${ }_{\text {MIP. A good similarity }}$ was showed between ITV $\mathrm{III}_{\text {II }}$ and ITV $\mathrm{IIP}_{\mathrm{P}}$, 4DCT is still a golden standard for the ITV delineation, but in the absence of 4DCT, image from 3DCT scan mode III and KV-CBCT may be considered for ITV delineation with caution.

Keywords: Non-small cell lung cancer (NSCLC); motion phantom; gross tumor volume (GTV); internal gross tumor volume; computed tomography

Submitted Aug 05, 2020. Accepted for publication Oct 27, 2020.

doi: $10.21037 / \mathrm{atm}-20-6246$

View this article at: http://dx.doi.org/10.21037/atm-20-6246 


\section{Introduction}

High precision radiation therapy (HPRT) allows a high dose of radiation to be delivered to the target volume while reducing the dose to organs at risk. However, the tumor motion induced by respiration during positioning and treatment delivery introduces a major challenge. In patients with non-small cell lung cancer (NSCLC) who undergo HPRT, accurate target delineation is of crucial importance.

Three-dimensional computed tomography (3DCT) is widely used in the delineation of target volume. However, high speed 3DCT with axial or helical mode always underestimates the tumor motion and distorts the reconstructed images of the thorax and abdomen (1). According to The International Commission on Radiation Units and Measurements Report 62 (ICRU62), to ensure dose coverage for mobile tumors, the internal target volume (ITV) includes the range of target motion during respiration on the basis of CTV (2). According to population-based motion information and guidelines, in conventional 3DCTbased treatment planning, the ITV is generated by drawing a margin on the basis of the gross tumor volume (GTV). However, the ITV contoured by this method is always larger than the real ITV, resulting in an overdose to normal tissue and geometric miss (3). Li et al. reported that the median degree of inclusion (DI) of planning target volume $(\mathrm{PTV})_{3 \mathrm{DCT}}$ in $\mathrm{PTV}_{4 \mathrm{DCT}}$ was $51.60 \%$, and the median DI of $\mathrm{PTV}_{4 \mathrm{DCT}}$ in $\mathrm{PTV}_{3 \mathrm{DCT}}$ was $99.94 \%$ for middle and lower lung cancer with free breathing (4).

Four-dimensional CT (4DCT), which allows data of full respiratory movement to be obtained, is widely used to assess respiration-induced tumor motion. After the 4DCT images have been acquired, a maximum-intensity projection (MIP) image is usually reconstructed to efficiently delineate the target volume $(5,6)$. The ITV generated from MIP images of 4DCT scans has been widely considered to be the golden standard for the definition of individual targets (7-9). However, because the individual ITVs acquired in 4DCT simulation are not always consistent with the real ITVs in radiation delivery, the accuracy of this technique has been questioned. Moreover, under the conditions of irregular breathing and lesion motion amplitude $>2 \mathrm{~cm}$, the accuracy of ITVs obtained with 4DCT is reduced further (10-13).

A cone-beam CT (CBCT) scanner mounted on the gantry of an accelerator with a scan time of approximately 60 seconds during image acquisition can be used to obtain respiration information. Previous studies have shown a good volume consistency between CBCT and 4DCT $(14,15)$. The visualized target volume in CBCT can be considered as an individual ITV which is similar to that of 4DCT. In the absence of

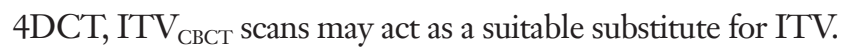

Though the 4DCT has been the golden technique to get individual ITV for SBRT of isolated lung cancer. It is difficult to abandon the isotropic margin accounting for the tumor motion in 3DCT based treatment planning. So, to investigate the individual ITV with different CT techniques and choose the optimal one or a combination of them is still a thing of great sense to do.

This study aimed to explore the volumetric and positional variations of GTV from different 3DCT scanning modes, and to compare the consistency of ITV between different 3DCT scan modes and CBCT and 4DCT by using a motion phantom and data from patients with NSCLC.

We present the following article in accordance with the MDAR reporting checklist (available at http://dx.doi. org/10.21037/atm-20-6246).

\section{Methods}

This study was approved by the Ethics Committee of Fujian Cancer Hospital, and written informed consent was obtained from all patients. All procedures performed in this study involving human participants were in accordance with the Declaration of Helsinki (as revised in 2013).

\section{Respiratory phantom study}

\section{Motion phantom}

The QUASAR ${ }^{\mathrm{TM}}$ Programmable Motion Phantom (Modus Medical Devices Inc., London, ON, Canada) with a cubic target simulating sinusoidal motion, was chosen, and is shown in Figure 1. Three motion amplitudes (A) were set $(5,10$, and $15 \mathrm{~mm})$, and three motion frequencies $(\mathrm{F})$ were set $(20,15$, and 10 times/min). The theoretical ITV can be calculated based on the given diameter, motion, and magnitude of the motion target.

\section{Patient characteristics}

The 3DCT and CBCT images of 12 NSCLC patients who had been treated with intensity-modified radiation therapy (IMRT) between 2011 January and 2014 December were retrospectively analyzed. The patients had a median age of 65 (range, 60-78) years old. All of the patients were pathologically confirmed and were considered unsuitable for surgery. The patient and tumor characteristics are shown in Table 1. 


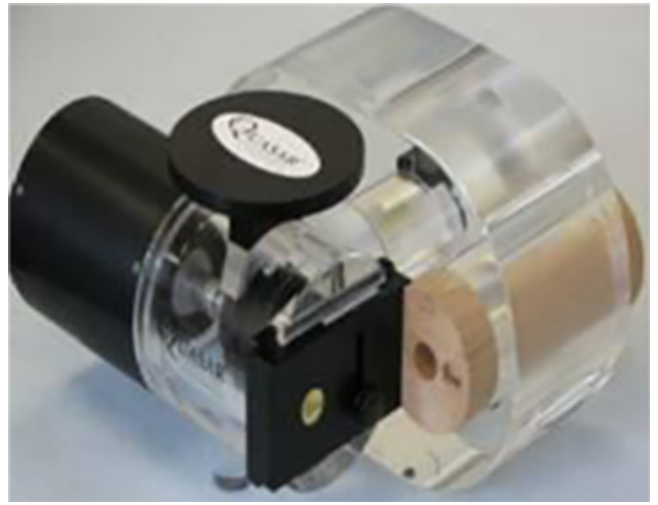

Figure 1 The motion phantom filled with air and a built-in polystyrene cube.

Table 1 Patient and tumor characteristics

\begin{tabular}{ll}
\hline Characteristics & Value \\
\hline Gender & 8 \\
Male & 4 \\
Female & \\
Age (years) & $60-78$ \\
Range & 65 \\
Median & \\
Location & 7 \\
Upper lobe & 5 \\
Lower lobe & \\
T stage & 4 \\
T1 & 5 \\
T2 & 3 \\
T3 & \\
Histology & 5 \\
Squamous cell carcinoma & 7 \\
Adenocarcinoma &
\end{tabular}

\section{Acquisition of CT images}

\section{DCT scanning of the phantom}

The 3DCT images were acquired with a Philips Brilliance CT Big Bore scanner (Philips Medical Systems, Inc., Cleveland, OH, USA). The phantom was placed on the scanning bed and used to simulate the movement of a lung tumor in the cranial-caudal (CC) direction. Three scan modes were set as follows: (I) pitch $=1.06$, rotation time
$=1.0 \mathrm{~s}$; (II) pitch $=0.813$, rotation time $=1.5 \mathrm{~s}$; and (III) pitch $=0.313$, rotation time $=1.5 \mathrm{~s}$. The 3 DCT scanning parameters were as follows: a $2-\mathrm{mm}$ slice thickness, $120 \mathrm{kV}$ scan voltage, and $398 \mathrm{~mA}$ electric current. The DICOM data of the moving phantom were reconstructed with a 1-mm slice thickness and transferred to the Pinnacle treatment planning system (Version 9.2).

\section{DCT scanning of the phantom}

For the 4DCT images, the motion parameters of the phantom were set as mentioned above. The scanning process involved a 50 -second scanning time and a slice thickness of $2 \mathrm{~mm}$. The respiratory signal was recorded by tracking the trajectory of the infrared markers placed on the phantom with the Real-time Position Management ${ }^{\mathrm{TM}}$ System (RPM, Varian Medical Systems, Palo Alto, CA, USA). The 4DCT images were sorted into 10 bins according to the phase of the breathing signal. MIPs of the 4DCT data sets were then generated and transferred to the Pinnacle treatment planning system (Version 9.2) to contour the ITV $\mathrm{IDCT}_{4 \mathrm{~T}}$.

\section{CBCT scanning of the phantom}

Cone-beam CTs were acquired using a Varian ${ }^{\circledR}$ Trilogy linear accelerator fitted with an On-Board Imager ${ }^{\circledR}(\mathrm{OBI})$ with system version 1.4.13.0 (Varian Medical Systems, PaloAlto, CA). The same setup, frequency settings, and slice thickness were used for CBCT scanning. The setting parameters were as follows: Super mode; collimator, S20, filter, F0; frame number, 1,320; frame clockwise rotation range of the rack, $-180^{\circ}$ to $+180^{\circ}$. The obtained images were reconstructed with a 1-mm slice thickness and transferred to the Pinnacle treatment planning system to contour the ITV $\mathrm{IBCT}_{\text {. }}$.

\section{DCT and CBCT scanning of the patients}

The 12 NSCLC patients were immobilized in the supine position with the arms raised above the head using vacuum bags. The 3DCT scanning was performed during free breathing using a Philips Brilliance CT Big Bore scanner (Philips Medical Systems, Inc., Cleveland, OH, USA). Images were reconstructed with a 2-mm slice thickness, and transferred to the Pinnacle treatment planning system. For the initial radiation treatment, CBCT scanning was used to verify the tumor position. The CBCT images were acquired by rotation from $-180^{\circ}$ to $+180^{\circ}$ and transmitted to the Pinnacle treatment planning system after reconstruction with a slice thickness of $2 \mathrm{~mm}$. 


\section{GTV contouring and ITV generation}

The GTV, ITV $\mathrm{IDCT}_{\text {D }}$ ITV by the same oncologist. The GTV was contoured under the same lung window conditions for each patient, with a window width of $1,600 \mathrm{Hu}$ and a window level of $-600 \mathrm{Hu}$. The ITV Свст was contoured with a window width of $400 \mathrm{Hu}$ and a window level of $40 \mathrm{Hu}$. The volume difference was calculated using the Dice similarity coefficient (Dsc) (16) and volume difference $(\Delta V)$. Dsc represents the degree of overlap between the two volumes, with the Dsc value approaching 1 as the agreement improves and if the two volumes do not overlap at all, the Dsc will be zero. The Dsc is used to evaluate the match index of the two volumes and is defined as follows:

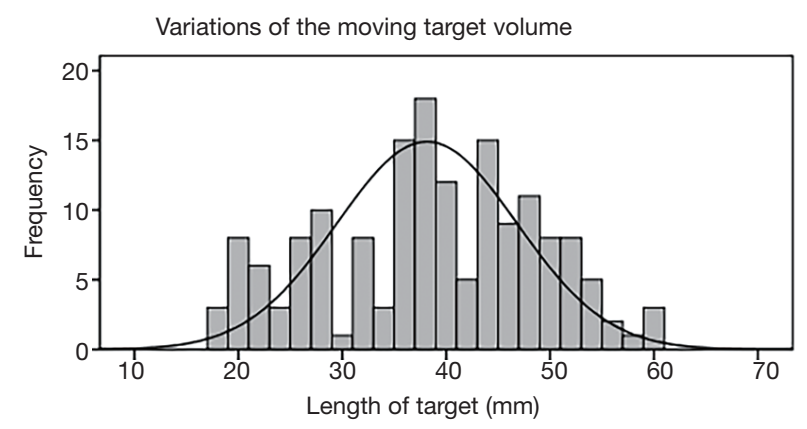

Figure 2 Length of the gross tumor volume (GTV) of the motion phantom acquired from three $3 \mathrm{DCT}$ scanning modes. The diameter of the cubic target was $30 \mathrm{~mm}$. The median length of the GTV was $38 \mathrm{~mm}$ (range, 18-59 mm).

$$
\left[D s c(A, B)=\frac{2(A \cap B)}{(A+B)}\right]
$$

$\Delta \mathrm{V}$ illustrates how the $\mathrm{A}$ is located within the $\mathrm{B}$ and is described as follows:

$$
\left[\Delta V(\%)=\frac{|A-B|}{A} \times 100 \%\right]
$$

\section{Statistical analysis}

All statistical analyses were performed using the SPSS17.0 package (SPSS Inc, Chicago, IL, USA). The Wilcoxon test was used to compare the tumor volumes and the central position gained by different scanning modes. Differences were considered to be significant if the $\mathrm{P}$ value was less than 0.05 .

\section{Results}

\section{Motion phantom study}

Geometrical variations of GTV from 3DCT scanning GTV was contoured on 162 series of 3DCT images, and the length of the GTV in the CC direction along with the target motion was analyzed. The median length of the GTV was $38 \mathrm{~mm}$ (range, 18-59 mm). The characteristics of GTV length are shown in Figures 2 and 3.

\section{Centroid position deviation derived from the three} 3DCT scanning modes

The position of the center of the mass (COM) in the
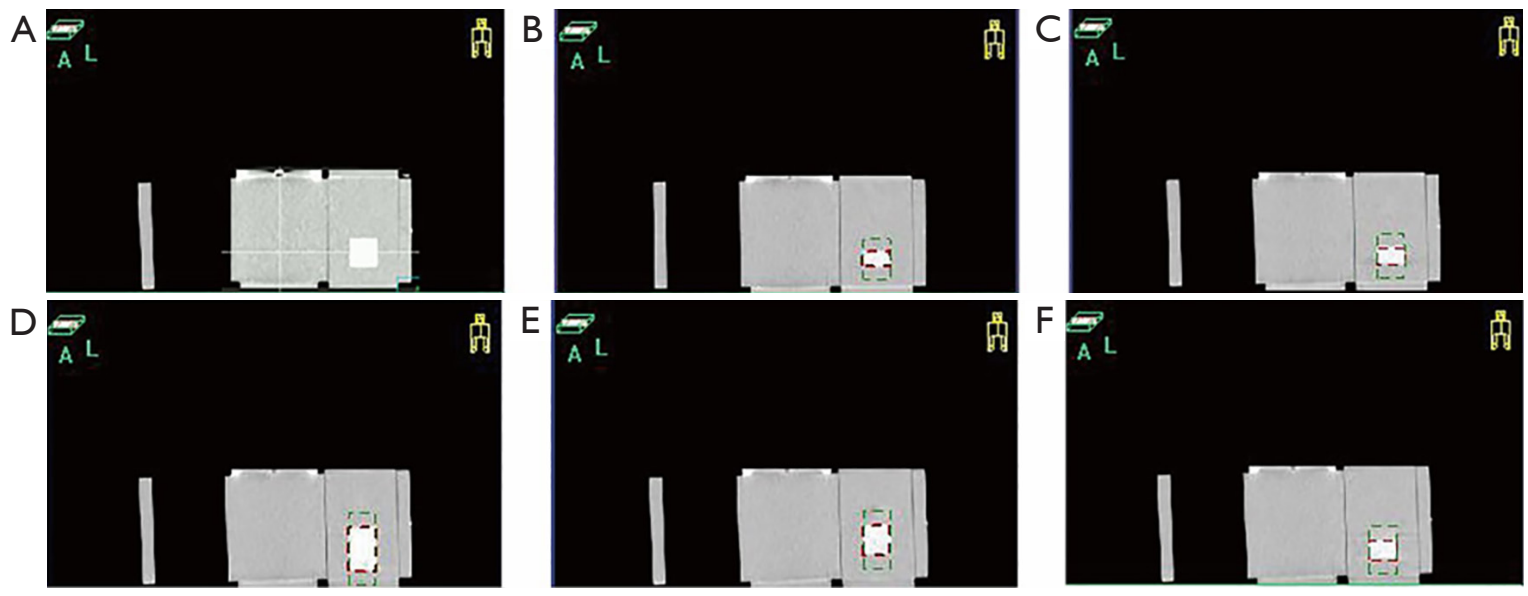

Figure 3 The gross tumor volume (GTV) variation under 3DCT scan mode I. The red outline depicts the GTV. (A) shows the cubic target within the motion phantom at conditions of rest; (B), (C), (D), and (E) show the length deviation of GTV under the same moving conditions: $\mathrm{A}=15 \mathrm{~mm}, \mathrm{~F}=15$ times/min. 


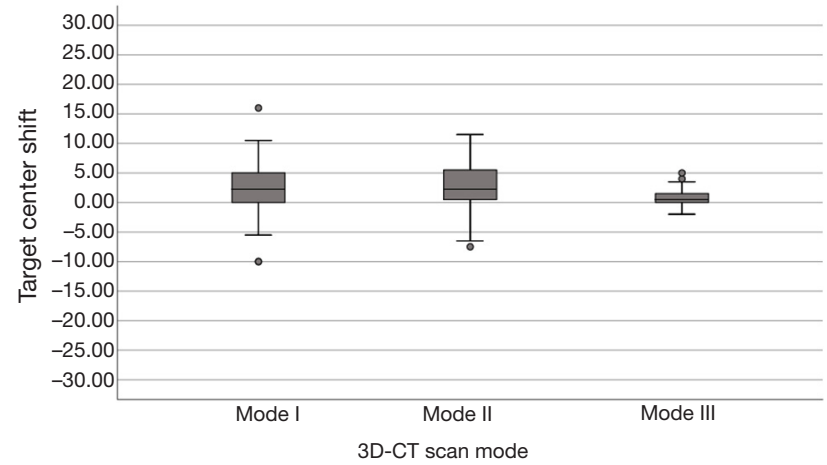

Figure 4 Central position deviations of gross tumor volume from different 3DCT scanning modes were $2.3 \pm 4.7 \mathrm{~mm}$ (range, $-10-16 \mathrm{~mm}$ ), $2.6 \pm 4.0 \mathrm{~mm}$ (range, $-5.5-11.5 \mathrm{~mm}$ ), and $1.0 \pm 1.4 \mathrm{~mm}$ (range, $-2-5 \mathrm{~mm})$, respectively $(\mathrm{P}<0.000)$.

CC direction was analyzed. The mobility vector in the $\mathrm{x}, \mathrm{y}$ direction was 0 , and the vector in the $\mathrm{z}$ direction was the amplitude of the phantom. Figures 4 and 5 show the deviation of the target center. As more respiration information was incorporated into scanning mode III, the mean deviation of COM derived was significantly smaller than that of scanning modes I and II $(\mathrm{P}<0.001)$. The variation in the centroid position of scan mode I, II and III were $2.3 \pm 4.7 \mathrm{~mm}$ (range, $-10-16 \mathrm{~mm}$ ), $2.6 \pm 4.0 \mathrm{~mm}$ (range, $-5.5-11.5 \mathrm{~mm}$ ), and $1.0 \pm 1.4 \mathrm{~mm}$ (range, $-2-5 \mathrm{~mm}$ ), respectively.

\section{The length of the ITV} $\mathrm{ITV}_{\text {СвСТ }}$ was positively correlated with the amplitude of the phantom. The ITV length from CBCT showed a deduction rate of $3.1-9.3 \%$ compared to that of 4DCT. The MIP derived from 4DCT with a clear visualization of the target without motion artifacts is taken as the golden standard for estimating the target motion. For the three amplitudes $(A=5 \mathrm{~mm}, 10 \mathrm{~mm}, 15 \mathrm{~mm})$, the mean ratio of ITV from CBCT to 4DCT was $0.97,0.91$, and 0.91 , respectively. Table 2 shows the characteristics of the $\mathrm{ITV}_{\mathrm{CBCT}}$.

\section{Comparison of the target length between ITV $_{3 \mathrm{DCT}}$, ITV $_{\text {СвCT }}$, and ITV}

Compared to those with scanning modes I and II, the ITV derived from scanning mode III showed a good consistency with ITV $\mathrm{IIP}_{\mathrm{P}}$ and $\mathrm{ITV}_{\mathrm{CBCT}}$, with a better DSC and smaller $\Delta \mathrm{V}$. The Dsc between $\mathrm{ITV}_{\mathrm{I}}, \mathrm{ITV}_{\mathrm{II}}, \mathrm{ITV}_{\mathrm{III}}$, and $\mathrm{ITV}_{\text {MIP }}$ were $0.78 \pm 0.77$ (range, $0.45-0.91$ ), $0.86 \pm 0.1$ (range, $0.57-0.99$ ), and $0.94 \pm 0.05$ (range, $0.77-1.0$ ), respectively.
The $\Delta \mathrm{V}$ between ITV $_{\text {I }}$ ITV II $_{\text {II }}$ ITV $_{\text {III }}$ and ITV $_{\text {MIP }}$ was $29.67 \%$ (range, $0-63.89 \%$ ), $17.22 \%$ (range, $0-57.45 \%$ ), $6.46 \%$ (range, $0-23.4 \%$ ), respectively (Figure 6). The mean ratio of $\mathrm{ITV}_{\mathrm{I}}$, ITV $\mathrm{II}$, ITV $\mathrm{III}$ to $\mathrm{ITV}_{\text {СBCT }}$ were $1.21,0.91$, and 1.06 , respectively, and the mean ratios to $\mathrm{ITV}_{\mathrm{MIP}}$ were $1.16,0.85$, and 0.95 , respectively. $\mathrm{ITV}_{\mathrm{I}}$ with a margin of 10-mm on CC direction and ITV $\mathrm{II}_{\text {II }}$ with a margin of $0-\mathrm{mm}$ on the basis of GTV showed poor consistency with ITV $\mathrm{CBCT}_{\mathrm{CBCT}}$ and $\operatorname{ITV}_{\text {MIP }}(\mathrm{P}<0.05)$. ITV III $_{\text {without a margin showed }}$ good consistency with $\operatorname{ITV}_{\text {MIP }}$ and $\operatorname{ITV}_{\text {СBCT }}(\mathrm{P}=0.044$ and $\mathrm{P}=0.082$, respectively). The data are shown in Table 3 .

\section{Patients}

CBCT and 3DCT were performed in 12 patients with lung cancer who had previously received IMRT. The $\mathrm{ITV}_{\mathrm{CBCT}}$ and $\mathrm{ITV}_{3 \mathrm{DCT}}$ [with a 1-cm extension on the CC direction, and a $0.5-\mathrm{cm}$ extension on the left-right (LR) and superior-inferior (SI) directions] were compared, and the volume difference between them was statistically significant $(\mathrm{P}=0.002)$. The difference between $\mathrm{ITV}_{\mathrm{CBCT}}$ and $\mathrm{ITV}_{3 \mathrm{DCT}}$ was expressed by $\mathrm{V}$, and the mean value of $\mathrm{V}$ was $35.4 \mathrm{~cm}^{3}$. The mean Dsc and $\Delta \mathrm{V}$ between $\mathrm{ITV}_{\text {3DCT }}$ and $\mathrm{ITV}_{\mathrm{CBCT}}$ were 0.50 and $60.76 \%$, respectively. Data was shown in Tables 4,5 and Figure 7.

\section{Discussion}

Physiologic motions, especially respiratory movement, are known to influence the precision of radiation procedures in the treatment of thoracic tumors. The images obtained by conventional 3DCT only represent the random shapes and volumes during the period of respiration and cannot truly reflect all of the necessary respiratory movement information. Slow scanning methods include slow spiral CT and CBCT, are more reproducible and can better capture tumor movement as a result of the larger CTV and a higher accuracy rate $(17,18)$. The ITV from 4DCT is a fusion of the GTVs contoured from the 10 respiratory phases during scanning and is considered to be the golden standard for ITV contouring (7-9).

In order to validate that the image from conventional 3DCT scan was the instant shape and volume of a phase from respiratory cycle that comes randomly, we applied three different 3DCT scanning modes by adjusting the pitch and rotation time to scan the phantom in our study. We found out the variation of the target volume and central position were significantly correlated with the scan mode. 

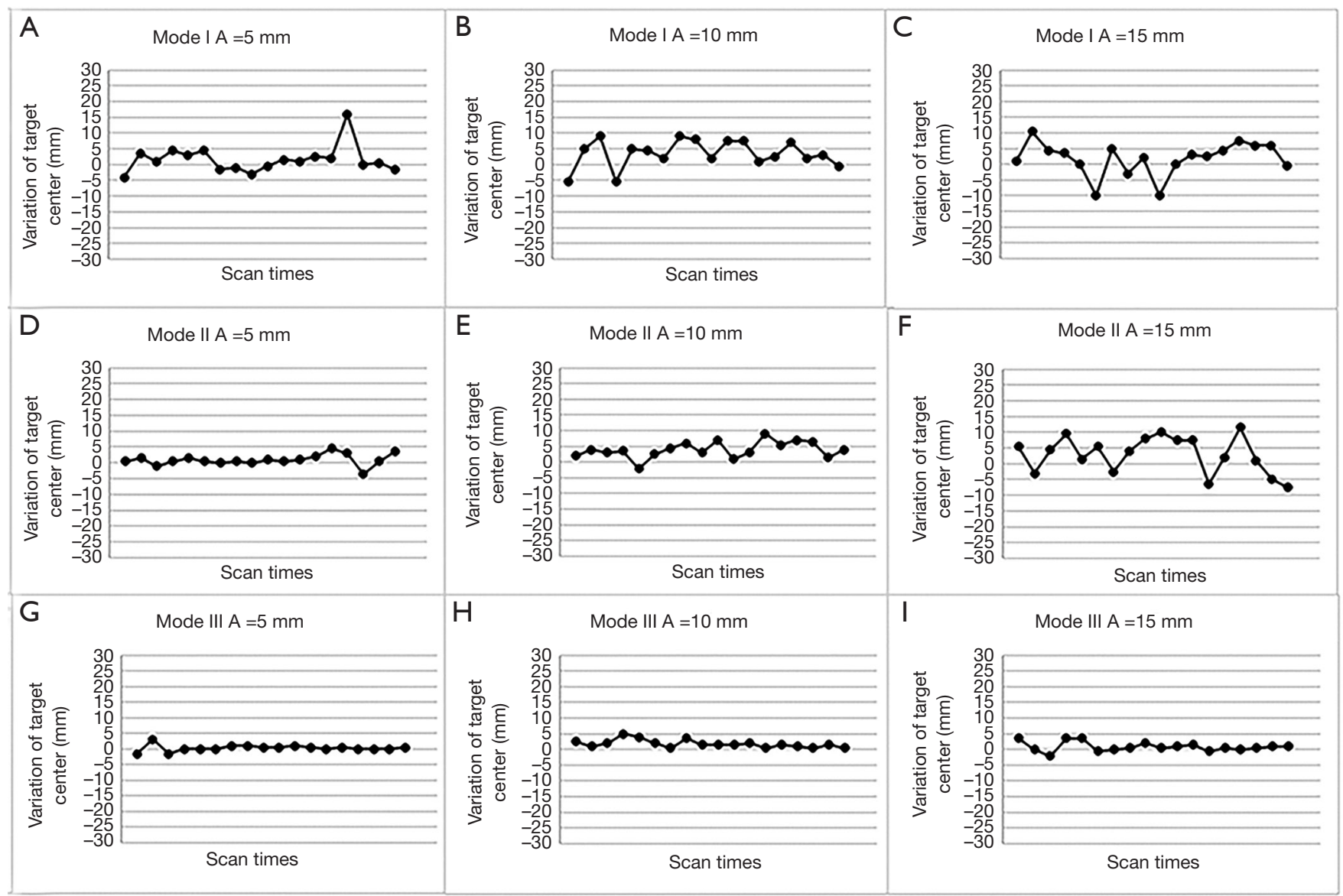

Figure 5 The centroid position deviation becoming stronger as the motion vector increases under the three 3DCT scanning modes. (A,B,C) The central deviation under scanning mode I with three amplitudes (A =5, 10, and $15 \mathrm{~mm})$. Mean \pm SD: $2.8 \pm 3.6(0-16.0 \mathrm{~mm}), 4.8 \pm 2.8$ (0-9.0 mm), and 4.4 $\pm 3.4(0-10.5 \mathrm{~mm})$, respectively $(\mathrm{P}=0.037)$. (D,E,F) The central deviation under scanning mode II with three amplitudes. Mean \pm SD: $1.4 \pm 1.3(0-4.5 \mathrm{~mm}), 4.2 \pm 2.2(1-9.0 \mathrm{~mm})$, and 5.7 $\pm 3.0(1-11.5 \mathrm{~mm})$, respectively $(\mathrm{P}=0.000)$. (G,H,I) The central position under scanning mode III had high reproducibility, with a central deviation of $0.6 \pm 0.8(0-3.0 \mathrm{~mm}), 1.8 \pm 1.3(0.5-5.0 \mathrm{~mm})$, and $1.2 \pm 1.1(0-3.5 \mathrm{~mm})$, respectively $(\mathrm{P}=0.03)$.

For the cubic target with a diameter of $30 \mathrm{~mm}$, the obtained length of the GTV varied greatly from $18-59 \mathrm{~mm}$. The ITV became larger as the motion amplitude increasing for scan mode II and III, while this relationship can't be detected by scan mode I. The mean and standard deviation of the centroid shift decreased as the scan time being longer for ITV I ITV $_{\text {II }}$ and ITV III with value of $2.3 \pm 4.7,2.6 \pm 4.0$, and $1.0 \pm 1.4 \mathrm{~mm}$, respectively. In this study, the motion cycle of the phantom was 3-6 seconds for three motion amplitudes. For scanning mode I with a pitch value of 0.813 and a rotation time of 1.0 seconds, the acquisition time was shorter than a motion cycle, leading to the great variation in centroid position and volume of GTV. While the scanning mode III with a smaller pitch value of 0.313 and a longer rotation time of 1.5 seconds resulted in a longer image acquisition time than the motion cycle. As more respiration information was incorporated into scanning mode III, the mean deviation of the central position and the target volume derived was significantly smaller than that of scanning modes I and II $(\mathrm{P}<0.001)$. We also found out that the deviation of central position became significantly greater as the motion amplitude increased $(\mathrm{P}<0.05)$ under same scanning mode. This result indicated that the tumor motion may contribute to increasing the target volume variation, because a tumor with larger motion amplitude is likely to produce more residual motion artifacts. Similar results were also reported by Chen et al. (1), who demonstrated that the volume and position of the targets obtained by conventional 
Table 2 The length of the ITV $\mathrm{CBCT}_{\text {compared to that of the ITV }}$ cIP

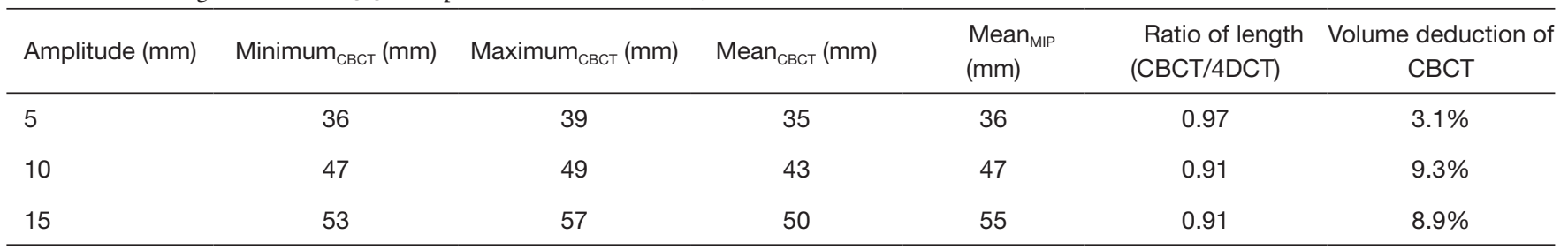

ITV $\mathrm{CBCT}_{\text {refers to the internal gross tumor volume of cone-beam computed tomography (CT); ITV }}$ MIP refers to the internal gross tumor volume of four-dimensional $\mathrm{CT}$; $\mathrm{Min}_{\mathrm{CBCT}}$ refers to the minimum length of ITV from cone-beam $\mathrm{CT}$; $\mathrm{Max}_{\mathrm{CBCT}}$ refers to the maximum length of ITV from cone-beam CT; Mean $_{\mathrm{CBCT}}$ refers to the mean length of ITV from cone-beam CT; Mean $_{\mathrm{MIP}}$ refers to the mean length of ITV from fourdimensional CT.
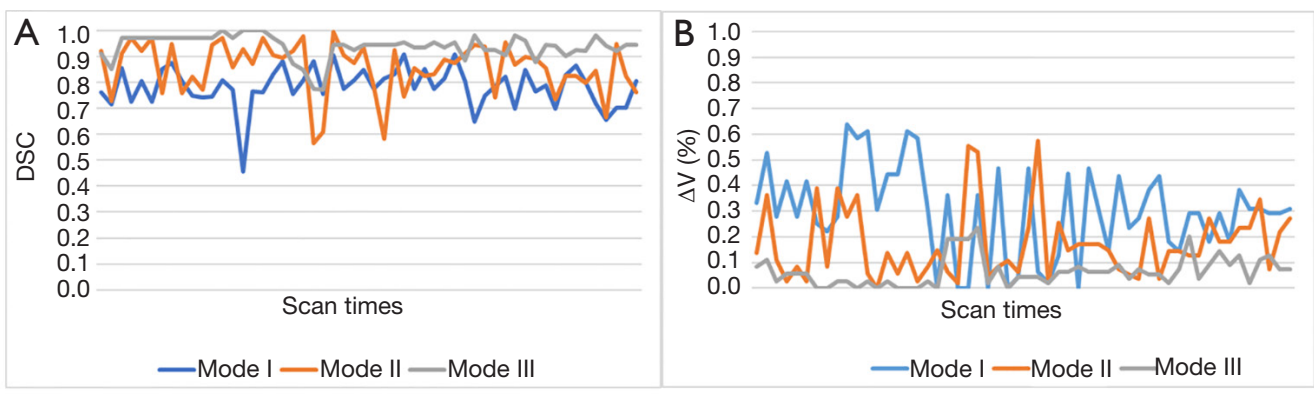

Figure 6 The Dsc and $\Delta \mathrm{V}$ of ITV from three 3D-CT scan modes. (A) The Dsc between ITV, ITV $_{\text {II }}$, ITV $_{\text {III }}$ and ITV MIP $_{\text {were }} 0.78 \pm 0.77$

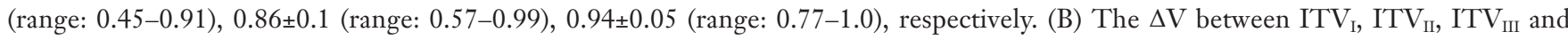

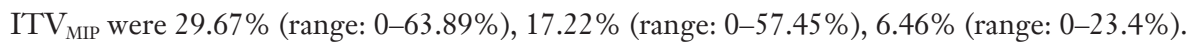

Table 3 Comparison of ITV 3 DCT with ITV $\mathrm{CBCT}_{\text {and }}$ ITV $\mathrm{MIP}_{\mathrm{P}}$ for the phantom

\begin{tabular}{|c|c|c|c|c|c|c|c|c|c|c|c|}
\hline $\begin{array}{l}\text { Amplitude } \\
(\mathrm{mm})\end{array}$ & $\mathrm{ITV}_{1}(\mathrm{CC})$ & $\mathrm{ITV}_{\|}(\mathrm{CC})$ & $\mathrm{ITV}_{\mathrm{III}}(\mathrm{CC})$ & $\operatorname{ITV}_{\mathrm{CBCT}}(\mathrm{CC})$ & ITV $\operatorname{IIP}_{\text {(CC) }}$ & $\begin{array}{l}\text { Mean ITV/ I } \\
\text { ITV }_{\text {Свст }}\end{array}$ & $\begin{array}{l}\text { Mean } \\
\left|T_{||} / \mathrm{ITV}_{\mathrm{CBCT}}\right|\end{array}$ & $\begin{array}{c}\text { Mean } \\
\text { ITV }_{\text {III }} / \mathrm{ITV}_{\text {CBCT }}\end{array}$ & $\begin{array}{c}\text { Mean } \\
\text { ITV }_{1} / \text { ITV }_{\text {MIP }}\end{array}$ & $\begin{array}{c}\text { Mean } \\
\text { ITV }_{\| I} / \text { ITV }_{\text {MIP }}\end{array}$ & $\begin{array}{l}\text { Mean ITV IIII } \\
\quad I_{\text {ITV }}\end{array}$ \\
\hline 5 & $\begin{array}{l}39.6-53.1 \\
(46.0 \pm 4.6)\end{array}$ & $\begin{array}{l}19.8-36.9 \\
(28.9 \pm 5.7)\end{array}$ & $\begin{array}{l}28.8-34.2 \\
(32.7 \pm 1.4)\end{array}$ & $\begin{array}{c}31.5-32.9 \\
(32.2 \pm 0.39)\end{array}$ & $\begin{array}{c}31.9-33.3 \\
(32.4 \pm 0.43)\end{array}$ & 1.43 & 0.92 & 1.06 & 1.42 & 0.89 & 1.01 \\
\hline 10 & $\begin{array}{c}36-62.1 \\
(48.5 \pm 9.5)\end{array}$ & $\begin{array}{c}18-44.1 \\
(34.4 \pm 7.9)\end{array}$ & $\begin{array}{l}32.4-42.3 \\
(38.9 \pm 3.0)\end{array}$ & $\begin{array}{c}35.6-40.5 \\
(39.9 \pm 0.44)\end{array}$ & $\begin{array}{c}41.4-43.2 \\
(42.3 \pm 0.46)\end{array}$ & 1.22 & 0.89 & 1.05 & 1.15 & 0.81 & 0.92 \\
\hline Overall & $\begin{array}{c}34.2-71.1 \\
(46.8 \pm 10.4)\end{array}$ & $\begin{array}{l}18-53.1 \\
(35 \pm 8.3)\end{array}$ & $\begin{array}{l}28.8-48.6 \\
(39.0 \pm 5.7)\end{array}$ & $\begin{array}{c}31.5-48.2 \\
(39.6 \pm 6)\end{array}$ & $\begin{array}{c}31.9-50.4 \\
(41.4 \pm 7)\end{array}$ & 1.21 & 0.91 & 1.06 & 1.16 & 0.85 & 0.95 \\
\hline Z & & & & & & -3.79 & -2.03 & -2.06 & -2.4 & -3.57 & -1.749 \\
\hline$P$ & & & & & & $<0.000$ & 0.041 & 0.044 & 0.016 & 0.000 & 0.082 \\
\hline
\end{tabular}

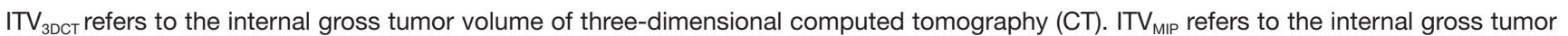
volume of four-dimensional CT; ITV refers to the internal gross tumor volume of 3DCT scan mode I, ITV ${ }_{\|}$refers to the internal gross tumor volume of 3DCT scan mode II, ITV III refers to the internal gross tumor volume of 3DCT scan mode III. 
Table 4 Comparison of ITV $_{10 \mathrm{~mm}}$ and ITVCBCT in lung cancer patients with 3DCT scanning mode I

\begin{tabular}{lcccc}
\hline Number & $\mathrm{GTV}_{\text {3DCT }}(\mathrm{CC})$ & $\mathrm{TV}_{10 \mathrm{~mm}}(\mathrm{CC})$ & $\mathrm{ITV}_{\text {СBCT }}(\mathrm{CC})$ & Volume difference $(\mathrm{CC})$ \\
\hline 1 & 6.1 & 25.5 & 5.7 & 19.8 \\
2 & 3.6 & 21.8 & 6.1 & 15.7 \\
3 & 12.7 & 40.2 & 16.7 & 23.5 \\
4 & 95.9 & 212.3 & 119.5 & 92.8 \\
5 & 6.5 & 29.7 & 11.0 & 18.7 \\
6 & 45.5 & 106.3 & 53.6 & 52.7 \\
7 & 1.3 & 10.6 & 1.6 & 9.0 \\
8 & 21.3 & 66.2 & 28.2 & 38 \\
9 & 51.0 & 122.7 & 60.2 & 62.5 \\
10 & 4.3 & 25.2 & 5.2 & 20.0 \\
11 & 11.4 & 32.8 & 15.0 & 17.8 \\
12 & 23.1 & 79.9 & 25.8 & 54.1 \\
Mean & - & - & - & 35.4 \\
\hline
\end{tabular}

ITV $10 \mathrm{~mm}$ : the internal gross tumor volume (ITV) of lung cancer with a 10-mm margin on the cranial-caudal (CC) direction, 5-mm on the leftright (LR) and superior-inferior (SI) directions on the basis of gross tumor volume (GTV). ITV $\mathrm{CBCT}_{\text {: }}$ The ITV of lung cancer from cone-beam computed tomography (CBCT).

Table 5 The Dice similarity coefficients (Dsc) and $\Delta \mathrm{V}$ of ITV $\mathrm{IBCT}_{\mathrm{C}}$ and $\mathrm{ITV}_{10 \mathrm{~mm}}$ of 12 patients

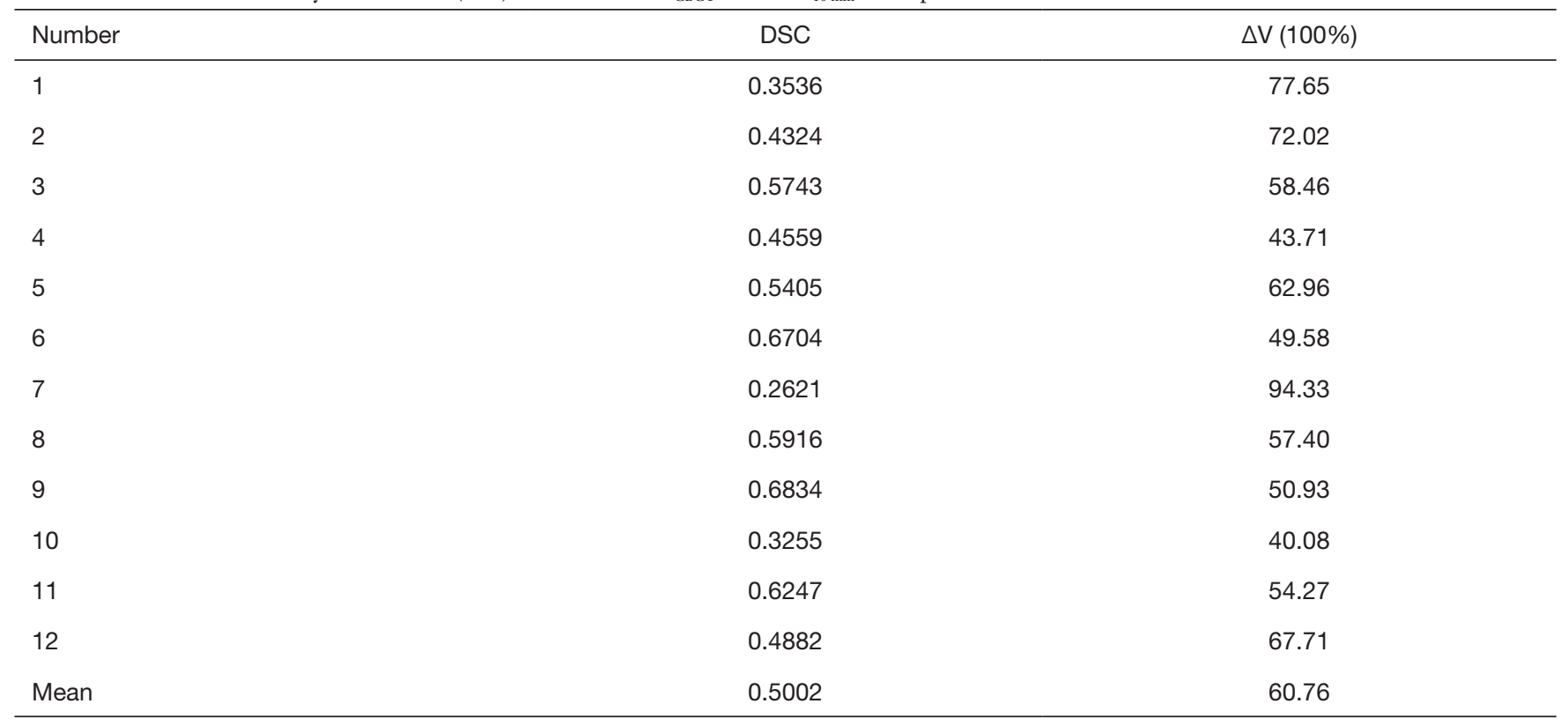

Dsc, dice similarity coefficient. $\Delta \mathrm{V}$ represents the delta volume of the two targets.

spiral CT scanning were obviously different and the obtained GTV was distorted after 3D reconstruction. Li (4) also evaluated the centroid shifts of PTVs derived from
3DCT and demonstrated the uncertainty of a target derived from 3DCT. In our study, we found the $\mathrm{GTV}_{\text {3DCT }}$ from scan mode I, II underestimate the MIP volume by $28 \%$, 

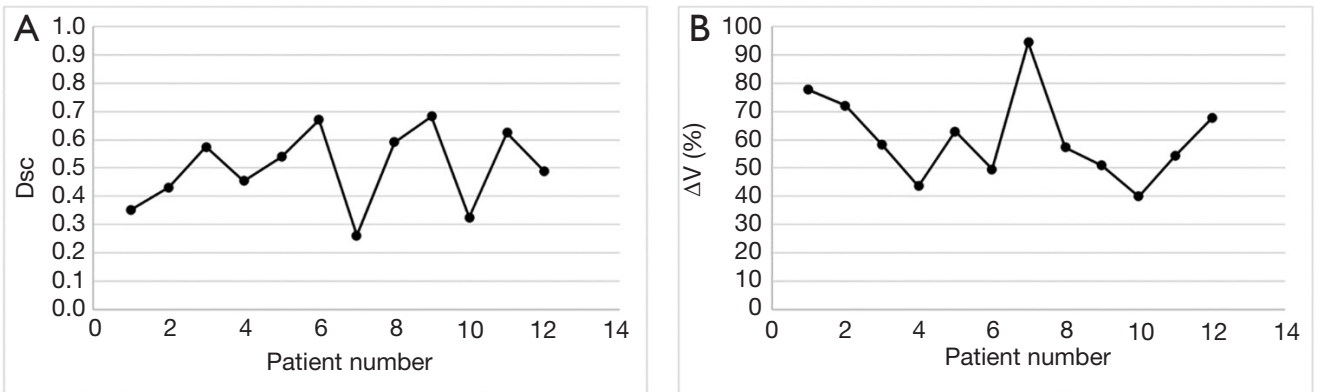

Figure 7 The Dsc and $\Delta \mathrm{V}$ of the 12 lung cancer patients. (A) Showed the Dsc distribution of the 12 patients with lung cancer, the mean Dsc was only 0.50 . (B) Showed the $\Delta \mathrm{V}$ between $\mathrm{ITV}_{3 \mathrm{D}-\mathrm{CT}}$ and $\mathrm{ITV}_{\mathrm{CBCT}}$ of 12 patients with lung cancer, the mean $\Delta \mathrm{V}$ was up to $60.7 \%$.

$15 \%$ respectively and they were statistically significant with $\mathrm{P}$ value of 0.000 . This result was similar to the previous study from Lingaiah et al. (15), who found that the GTV by helical mode scanning underestimate the MIP volume by $13 \%$ and $21 \%$ respectively and was statistically significant with a $P$ value of 0.00 . In addition, our study showed the $\mathrm{GTV}_{\text {3DCT }}$ from scan mode III underestimate the MIP volume only by $5 \%$ and this difference was no statistically significant $(\mathrm{P}=0.082)$. Thus, scan mode III could effectively decrease the uncertainty and variation from the variation of respiration. This certainly due to the smaller pitch value and longer rotation time of scan mode III which guarantee much more time to acquire much more target motion information.

By analyzing the Dsc and $\Delta \mathrm{V}$ between targets, the difference in ITV obtained through different imaging techniques can be more clearly established. The Dsc between targets was directly influenced by the shift of the target central position. In our study, we evaluated the Dsc between

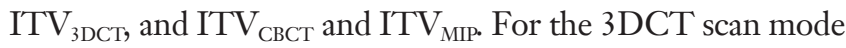
I and II, the ITV obtained was much larger than the ITV or ITV $\mathrm{TIP}_{\mathrm{PI}}$ for the phantom. A good similarity between ITV and $\mathrm{ITV}_{\mathrm{MIP}}$ with a mean Dsc and $\Delta \mathrm{V}$ of 0.94 and $6.46 \%$ was showed in our study. The mean ratio of ITV $_{\text {III }}$ to ITV $\mathrm{IBBCT}_{\mathrm{CBC}}$ and ITV $\mathrm{IIP}_{\text {was }} 1.06$ and 0.95 , respectively. The present data suggest that scanning mode III, with a pitch of 0.313 and rotation of 1.5 seconds, could obtain considerably more respiration information and had a good consistency with 4DCT. The ITVs from scan mode III may be considered as individual ITVs for IMRT in lung cancer.

The data of 12 patients with lung cancer who had previously received radiotherapy were also analyzed. The defined $\mathrm{ITV}_{3 \mathrm{DCT}}$ with a margin of $10 \mathrm{~mm}$ in the CC direction and $5 \mathrm{~mm}$ in the SI and LR directions showed an increasing volume of $35.27 \mathrm{~cm}^{3}$ and a mean size ratio of
3.1 compared to ITV $\mathrm{IBCT}_{\text {Св. }}$ Poor consistency was revealed

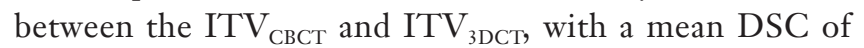
0.50 and $\Delta \mathrm{V}$ of $60 \%$. These results support those of some previous studies $(3,19,20)$. For instance, Li et al. investigated thirty-one patients with NSCLC underwent 3DCT and CBCT scans of the thorax during free breathing and found the mean Dsc between the two image modalities was 0.66 and the ratio of $\mathrm{ITV}_{3 \mathrm{DCT}}$ to $\mathrm{ITV}_{\mathrm{CBCT}}$ was 2.33 . For the 12 patients undergo 3DCT scan mode $\mathrm{I}$, the corresponding ITV derived was much larger than the $\mathrm{ITV}_{\mathrm{CBCT}}$, which resulted in good coverage of tumor motion while carrying a high possibility of unnecessary irradiation to normal tissue.

CBCT images may suffer from projection deduction due to the interplay between the gantry rotation and the motion target. The volume from CBCT possessed great reproducibility for a certain amplitude in this study, this suggested that the image projection deduction may have no correlation with the amplitude of motion. In our study, the ITV obtained from CBCT showed a volume deduction of $3.1-9.3 \%$ compared to the ITV obtained from the MIP image of 4DCT. This result was similar to those of some reports; for instance, Wang et al. (14) reported a volume difference of less than $8 \%$. Our study showed that the volume ratio of CBCT to 4DCT was 0.93. Lingaiah et al. (15) reported that CBCT was well correlated with the 4DCT volume, with a ratio of 1.02. Although the $\mathrm{ITV}_{\mathrm{CBCT}}$ was slightly smaller than the $\mathrm{ITV}_{4 \mathrm{DCT}}$, it contained considerably more respiratory information due to its longer scan time.

Previous studies $(10,21)$ have reported that under sinusoidal breathing conditions, CBCT and 4DCT can realistically reflect the actual range of tumor respiratory motion; however, when the respiratory amplitude is too large, or the respiratory curve is irregular, the ITVs obtained by CBCT and 4DCT are often partially deleted, 
making them smaller than that of the theoretical ITV. Under such conditions, the volumes of CBCT and 4DCT can be reduced by $20-30 \%$ and the length of the ITV can be reduced by 7-11 $\mathrm{mm}$. Our study also evaluated the difference in ITV gained from different CT scans and came to a similar conclusion.

In this article, we verified the randomness of GTV from 3DCT scanning and investigate the deviation of ITV from different 3DCT scan modes and different CT scan techniques. There is still much work to do to improve the techniques of 3DCT and 4DCT and to explore a optimized combination of these techniques.

Our study has some limitations that need to be addressed. First, the study used only three sinusoidal phantom motions, which were constrained to the CC direction, and the data of the patients involved were collected and analyzed retrospectively. In addition, though we set strict criteria for collecting the patients' data, the 12 number of the patients was also limited. These situations are certainly ideal; however, it may not be the case in a clinical setting. Further investigations involving 3D target motion and nonsinusoidal motion patterns as well as a larger amount of real patients' breathing patterns between 3DCT scanning mode III, CBCT, and 4DCT would be worthwhile.

\section{Conclusions}

Our results indicated a good correlation between the ITV got from 3DCT scan mode III and MIP volume. The ITV from CBCT showed a deduction rate of 3.1-9.3\% compared to 4DCT. In cases where 4DCT scan imager is not possible, this "slow" 3DCT scan mode III or CBCT scan may be considered for determining ITV volumes, with a small additional isotropic margin for safer treatment. The GTV obtained from 3DCT scan mode I had a strong uncertainty, and the target centroid position deviated with great randomness; the ITV formed on the basis of this $\mathrm{GTV}_{3 \mathrm{DCT}}$ was larger than the $\mathrm{ITV}_{\mathrm{CBCT}}$ or $\mathrm{ITV}_{4 \mathrm{DCT}}$, which may lead to geographical miss radiation of the target and excessive radiation of surrounding normal tissue.

\section{Acknowledgments}

None.

\section{Footnote}

Reporting Checklist: The authors have completed the MDAR reporting checklist. Available at http://dx.doi.org/10.21037/ atm-20-6246

Data Sharing Statement: Available at http://dx.doi. org/10.21037/atm-20-6246

Conflicts of Interest: All authors have completed the ICMJE uniform disclosure form (available at http://dx.doi. org/10.21037/atm-20-6246). The authors have no conflicts of interest to declare.

Ethical Statement: The authors are accountable for all aspects of the work in ensuring that questions related to the accuracy or integrity of any part of the work are appropriately investigated and resolved. This study was approved by the Ethics Committee of Fujian Cancer Hospital, and written informed consent was obtained from all patients. All procedures performed in this study involving human participants were in accordance with the Declaration of Helsinki (as revised in 2013).

Open Access Statement: This is an Open Access article distributed in accordance with the Creative Commons Attribution-NonCommercial-NoDerivs 4.0 International License (CC BY-NC-ND 4.0), which permits the noncommercial replication and distribution of the article with the strict proviso that no changes or edits are made and the original work is properly cited (including links to both the formal publication through the relevant DOI and the license). See: https://creativecommons.org/licenses/by-nc-nd/4.0/.

\section{References}

1. Chen GT, Kung JH, Beaudette KP. Artifacts in computed tomography scanning of moving objects. Semin Radiat Oncol 2004;14:19-26.

2. Wambersie A, Landberg T. ICRU report 62, prescribing, recording and reporting photon beam therapy (supplement to ICRU Report 50). ICRU News. 1999.

3. Li F, Li J, Xing J, et al. Analysis of the advantage of individual PTVs defined on axial 3D CT and 4D CT images for liver cancer. J Appl Clin Med Phys 2012;13:4017.

4. Li FX, Li JB, Zhang YJ, et al. Comparison of the planning target volume based on three-dimensional CT and fourdimensional CT images of non-small-cell lung cancer. Radiother Oncol 2011;99:176-80.

5. Underberg RW, Lagerwaard FJ, Slotman BJ, et al. Use of 
maximum intensity projections (MIP) for target volume generation in 4DCT scans for lung cancer. Int J Radiat Oncol Biol Phys 2005;63:253-60.

6. Mori S, Kanematsu N, Asakura H, et al. Projectiondata based temporal maximum attenuation computed tomography: determination of internal target volume for lung cancer against intra-fraction motion. Phys Med Biol 2007;52:1027-38.

7. Cai J, Read PW, Sheng K. The effect of respiratory motion variability and tumor size on the accuracy of average intensity projection from four-dimensional computed tomography: an investigation based on dynamic MRI. Med Phys 2008;35:4974-81.

8. Hughes S, McClelland J, Chandler A, et al. A comparison of internal target volume definition by limited fourdimensional computed tomography, the addition of patient-specific margins, or the addition of generic margins when planning radical radiotherapy for lymph node-positive non-small cell lung cancer. Clin Oncol (R Coll Radiol) 2008;20:293-300.

9. Gabryś D, Kulik R, Trela K, et al. Dosimetric comparison of liver tumour radiotherapy in all respiratory phases and in one phase using 4DCT. Radiother Oncol 2011;100:360-4.

10. Clements N, Kron T, Franich R, et al. The effect of irregular breathing patterns on internal target volumes in four-dimensional CT and cone-beam CT images in the context of stereotactic lung radiotherapy. Med Phys 2013;40:021904.

11. Britton KR, Starkschall G, Tucker SL, et al. Assessment of gross tumor volume regression and motion changes during radiotherapy for non-small-cell lung cancer as measured by four-dimensional computed tomography. Int J Radiat Oncol Biol Phys 2007;68:1036-46.

12. James SS, Mishra P, Hacker F, et al. Quantifying ITV instabilities arising from 4DCT: a simulation study using patient data. Phys Med Biol 2012;57:L1-7.

13. Pötter R, Georg P, Dimopoulos JC, et al. Clinical

Cite this article as: Wang Y, Liu T, Chen H, Bai P, Zhan Q, Liang X. Comparison of internal target volumes defined by three-dimensional, four-dimensional, and cone-beam computed tomography images of a motion phantom. Ann Transl Med 2020;8(22):1488. doi: 10.21037/atm-20-6246 outcome of protocol based image (MRI) guided adaptive brachytherapy combined with $3 \mathrm{D}$ conformal radiotherapy with or without chemotherapy in patients with locally advanced cervical cancer. Radiother Oncol 2011;100:116-23.

14. Wang Z, Wu QJ, Marks LB, et al. Cone-beam CT localization of internal target volumes for stereotactic body radiotherapy of lung lesions. Int J Radiat Oncol Biol Phys 2007;69:1618-24.

15. Lingaiah R, Ali MA, Kulsum U, et al. GTV volume estimation using different mode of computer tomography for lung tumors in stereotactic body radiation therapy. Polish Journal of Medical Physics Engineering 2019;25:29-34.

16. van Dam IE, van Sörnsen de Koste JR, Hanna GG, et al. Improving target delineation on 4-dimensional CT scans in stage I NSCLC using a deformable registration tool. Radiother Oncol 2010;96:67-72.

17. Lagerwaard FJ, Van Sornsen de Koste JR, Nijssen-Visser MR, et al. Multiple "slow" CT scans for incorporating lung tumor mobility in radiotherapy planning. Int J Radiat Oncol Biol Phys 2001;51:932-7.

18. van Sörnsen de Koste JR, Lagerwaard FJ, NijssenVisser MR, Graveland WJ, et al. Tumor location cannot predict the mobility of lung tumors: a 3D analysis of data generated from multiple CT scans. Int J Radiat Oncol Biol Phys 2003;56:348-54.

19. Underberg RW, Lagerwaard FJ, Cuijpers JP, et al. Four-dimensional CT scans for treatment planning in stereotactic radiotherapy for stage I lung cancer. Int J Radiat Oncol Biol Phys 2004;60:1283-90.

20. Li F, Li J, Ma Z, et al. Comparison of internal target volumes defined on 3-dimensional, 4-dimensonal, and cone-beam CT images of non-small-cell lung cancer. Onco Targets Ther 2016;9:6945-51.

21. Vergalasova I, Maurer J, Yin FF. Potential underestimation of the internal target volume (ITV) from free-breathing CBCT. Med Phys 2011;38:4689-99. 